\title{
Pacientes Trans e Cuidado Multiprofissional em Centros de Atendimento
}

\section{Psicossocial}

\author{
Trans Patients and Multiprofessional Care within Psychosocial Care Centers \\ Pacientes Trans y Atención Multiprofesional en Centros de Atención Psicosocial \\ José Bernardes da Silva Filho \\ Fundação Escola de Saúde Pública de Palmas (FESP), Palmas, TO, Brasil
}

Ana Carolina Peixoto do Nascimento

Universidade Federal do Tocantins (UFT), Palmas, TO, Brasil

Gustavo Henrique Carvalho de Castro

Universidade de Brasília (Unb), Brasília, DF, Brasil

\begin{abstract}
Resumo
Considerando a discriminação social contra pessoas trans como um determinante para o sofrimento psíquico, este trabalho objetiva analisar a assistência à saúde mental da população trans em dois Centros de Atenção Psicossocial (CAPS) de uma capital brasileira. Entrevistas com nove trabalhadores da equipe multiprofissional possibilitaram identificar práticas, crenças e percepções que permeiam este cuidado. A interpretação dos relatos foi pautada pela análise hermenêutico-dialética. Identifica-se que, mesmo as equipes compreendendo as demandas de saúde mental de pacientes trans como atreladas à discriminação, à violência e à marginalização, são remanescentes compreensões arraigadas em estereótipos, tal como a de que equidade para pacientes trans implicaria privilégio. Consoante à literatura sobre acesso de pessoas trans à saúde pública, o nome social também se afirmou como prática de acolhimento fundamental, porém, insuficiente quando dissociada do maior preparo das equipes nas etapas subsequentes ao atendimento. Sugere-se que a efetividade do cuidado trilha pela garantia do processo terapêutico humanizado, considerando iniquidades sociais enfrentadas (como preconiza o Sistema Único de Saúde) por pacientes trans.
\end{abstract}

Palavras-chave: Pessoas trans; Centros de Atenção Psicossocial; Assistência à saúde.

\begin{abstract}
Considering social discriminationagainst transgender people as a determinant for psychological suffering, this work analyzes the mental health assistance of the trans population in two Psychosocial Care Centers in a Brazilian capital. Interviews with nine workers from the multiprofessional team made possible identify practices, beliefs and perceptions that permeate this care. The interpretation was based on the hermeneutic-dialectic analysis. It is identified that, even though teams understanding the mental health demands of trans patients as linked to discrimination, violence and marginalization, understandings that remain rooted in stereotypes remain, such as that equity for trans patients would imply
\end{abstract}


privilege. Depending on the literature about transgender people and public health, the social name also asserted itself as a welcoming practice, however, insufficient when dissociated from the greater preparation in the subsequent stages of care. It is suggested that the effectiveness of care leads to the guarantee of the humanized therapeutic process, considering social inequities faced (as recommended by SUS) by trans patients.

Keywords: Transpeople; Psychosocial Care Centers; Health care.

\section{Resumen}

Considerando ladiscriminación social de las personas trans como factor determinante delsufrimiento psicológico, este trabajo analisa laasistencia de salud mental de lapoblacióntransen dos Centros de AtenciónPsicosocialen una capital brasileña. Nueve entrevistas conel equipo multiprofesionalhan identificado prácticas, creencias y percepciones que impregnanestaatención. La interpretación se basóenelanálisishermenéutico-dialéctico. Se identifica que, a pesar de que losequiposentiendenlas demandas de salud mental de los pacientes trans como vinculados aladiscriminación, laviolencia y lamarginación, losentendimientos enraizados enlosestereotipospermanecen, como que laequidad para los pacientes transimplicaríaun privilegio. El nombre social también se afirmó como una prácticabienvenida, sin embargo, insuficiente cuando se disocia de lapreparaciónenlas etapas

posteriores. Se sugiere que laefectividad de laatención depende de lagarantíadelprocesoterapéutico humanizado, considerando las desigualdades sociales que enfrentan (según recomenda el SUS) por los pacientes trans.

Palabras clave: Personas trans; Centros de atenciónpsicosocial; Cuidado de lasalud.

\section{Introdução}

A saúde é uma garantia social, e um dever do Estado para com todos os cidadãos brasileiros. Conforme o Artigo 196 da Constituição Federal de 1988 e regulamentação dada pela Lei $n^{\circ} 8.080 / 90$, a qual dispõe sobre o Sistema Único de Saúde (SUS), são princípios norteadores da garantia desse direito: integralidade, universalidade, igualdade da assistência à saúde (sem nenhuma discriminação/privilégio) e equidade. Nesse sentido, o cuidado a que o SUS se propõe é perpassado pelo atendimento a todo sujeito, independentemente de sua identidade de gênero e/ou orientação sexual (Brasil, 1988; 1990).

Em 2011, reconhecendo a discriminação por identidade de gênero e/ou orientação sexual como determinante social de saúde (que influi em processos de saúde/doença), foi instituída a "Política Nacional de Saúde Integral LGBT" nas práticas do SUS (Brasil, 2013), objetivando o fomento à saúde integral da população LGBT (Lésbicas, Gays, Bissexuais, Travestis e Transexuais). Tal 
política tem sido um pilar no combate à discriminação e ao preconceito, partindo de um serviço de saúde não só integral, universal e igualitário, mas principalmente equitativo (Rocon, Wandekoken, Barros, Duarte, \& Sodré, 2020).

No que compete à população trans (transgêneros, travestis e transexuais), podem ser reconhecidos alguns avanços no que diz respeito à assistência à saúde deste grupo. A portaria 1.820/2009, por exemplo, assegura o direito da pessoa trans ser identificada nos serviços de saúde por seu nome social, ou seja, o nome que preferir (Brasil, 2012a). Outra conquista, dada através da Portaria 1.707/2008, foi o acesso ao Processo Transexualizador em âmbito do SUS (Brasil, 2008), que orienta para a atenção integral a mulheres transexuais que desejam realizar modificações corporais. Tal processo, redefinido e ampliado em 2013, se estendeu também às travestis e aos homens transexuais, tornando-se um relevantedispositivocatalisador da "Política Nacional de Saúde Integral LGBT”, com enfoque na população trans (Brasil, 2013).

Ressalta-se que são transexuais aqueles ou aquelas que reivindicam um reconhecimento tanto social como legal, seja para o gênero feminino ou masculino (Bento, 2008). Mas definir transexuais, Rev. Polis e Psique, 2021; 11(3): 56 - 80 travestis e transgêneros não é simples, posto que travestis e transexuais, embora estejam na categoria de sujeitos que transcendam as normas de gênero, são identidades de gênero distintas, que se constroem em diferentes contextos sociais e realidades.

Namaste (2006) define transexuais como pessoas que se identificam com o sexo oposto ao seu sexo biológico. Para a autora, transgênero é um termo que abarca todas as outras identidades que não estão na norma de sexo e gênero. Segundo Bento (2017), transexuais constroem um sentido de identidade de gênero a partir do que sentem em suas histórias de vida, não existindo uma regra em comum para uma definição de suas experiências. Alguns/algumas se definem como transexuais apenas a partir de transformações hormonais, já para outros/outras a cirurgia é necessária para a construção da identidade.

As travestis performam identidades femininas e masculinas, indo além de apenas transitar entre o oposto de seu sexo biológico (Thanem \& Wallenberg, 2014), e embora se sintam em parte como mulher, "normalmente não pretendem realizar a SRS [cirurgia de redesignação sexual]. Vivem na condição feminina e masculina e, não necessariamente são pessoas 
prostituídas [...]" (Bento, 2008, p. 70). As travestis, diferente das pessoas transexuais, questionam o binarismo de sexo e gênero ao apresentar características masculinas e femininas simultaneamente, não desejando estacionar em um pólo binário (Thanem \& Wallenberg, 2014).

Apesar das conquistas, a população trans, dentro do acrônimo LGBT, é uma das "que mais enfrenta dificuldades para acessar os serviços de saúde, da atenção básica à alta complexidade" (Rocon e cols., 2020, p. 2). Segundo Mello, Perilo, Braz e Pedrosa (2011), isso se dá ao longo dos diferentes serviços e equipamentos de saúde, sendo que diversas modalidades de transfobia, cada vez mais frequentes, terminam por afastá-los/as. Mais do que um rechaço social às pessoas trans, transfobias são estigmas, preconceitos e/ou atos discriminatórios enraizados na conformidade entre gênero e sexo biológico (Davis, 2009).

Em um dos estudos pioneiros sobre os desafios do acesso à saúde pela população trans, Muller e Knauth (2008, p. 13) observaram que, em geral, "os locais de atendimento tornam-se mais um lugar de discriminação, o que contraria os princípios do SUS”. E mesmo em estudos mais recentes, o acesso à saúde pública pela população trans tem sido um desafio, Rev. Polis e Psique, 2021; 11(3): 56 - 80 persistindo: episódios de discriminação e patologização da transexualidade; baixa qualificação dos profissionais frente às demandas das pessoas trans; acolhimento inadequado/insuficiente; falta de recursos para o desenvolvimento dos programas e ações de promoção à saúde das pessoas trans; e vínculo precário entre o profissional de saúde e o paciente trans (Sehnem, Rodrigues, Lipinski, Vasquez, \& Schmidt, 2017; Rocon e cols., 2018; Rocon e cols., 2020).

Como salientam Sehnem e cols (2017), tendo por referência a Atenção Primária em Saúde (APS), um quadro como esse desestrutura a integralidade da atenção e a equidade do cuidado em saúde. Sem desconsiderar que mitos e estigmas com relação à saúde da população trans são constantemente reificados e existe o desconhecimento dos próprios profissionais acerca das políticas públicas para contemplar a população trans (Sehnem e cols., 2017).

Segundo Lionço (2008) - ao se referir à Estratégia de Saúde da Família (ESF) -, a integralidade e universalidade da saúde no Brasil são ideais de um país atravessado por injustiças que promovem discriminação, impossibilitando a equidade no SUS para a população trans. Para Lionço (2008), o adoecimento dessa 
população é determinado pelas variáveis sociais, e não por suas identidades de gênero e/ou orientação sexual.

Assim, há tanto baixa procura de travestis e transexuais em diversos equipamentos de saúde (Muller \& Knauth, 2008; Sehnem e cols., 2017), como a população trans tem alta propensão à vulnerabilidade e ao sofrimento psíquico (Corrêa, Rodrigues, Mendonça, \& Cruz, 2020), o que possibilita problematizar como se daria a assistência à saúde mental de pessoas trans no contexto dos Centros de Atenção Psicossociais (CAPS). Oriundos da Política Nacional de Saúde Mental dos SUS, formulada em 2001, os CAPS servem ao tratamento de portadores de transtornos mentais, que, objetivando superar um processo ainda assistencialista, buscam fomentar a produção de saúde e de laços sociais (Tenório, 2002).

Portanto, o objetivo deste estudo é o de analisar a assistência à saúde mental da população trans em dois Centros de Atenção Psicossocial (CAPS) de uma capital brasileira. Entrevistas semiestruturadas com nove trabalhadores das equipes multiprofissionais possibilitaram identificar práticas, crenças e percepções que permeiam este cuidado. A pesquisa fundamenta-se na literatura sobre o acesso por pessoas trans à saúde Rev. Polis e Psique, 2021; 11(3): 56 - 80 pública no Brasil (Arán, Murta, \& Lionço, 2008; Corrêa e cols., 2020; Lionço, 2008; Mello e cols., 2011; Muller \& Knauth, 2008; Rocon, Rodrigues, Zamboni, \& Pedrini, 2016; Rocon e cols., 2018; Rocon e cols., 2020; Sehnem e cols., 2017), e busca sublinhar a práxis e perspectiva dos profissionais que atuam nos CAPS.

Assim, o trabalho se justifica na medida em que entende, conforme os princípios do SUS, que tais espaços foram criados para serem locais de acolhimento e atendimento pautado na equidade. No entanto, tais espaços, muitas vezes, violam os direitos de populações trans, resultando na baixa procura desse grupo pelos serviços de saúde - representando um fator de risco para a saúde mental desses sujeitos (Muller \&Knauth, 2008; Sehnem e cols., 2017).

\section{Caminho Metodológico}

A presente pesquisa utilizou a abordagem qualitativa, a qual abarca estudos “[...] capazes de incorporar a questão do significado e da intencionalidade como inerentes aos atos, às relações, e às estruturas sociais, sendo essas últimas tomadas tanto no seu advento quanto na sua transformação, como 
construções humanas significativas” (Minayo, 2002, p. 10).

A presente pesquisa foi validada por Comitê de Ética em Pesquisa. Participaram do estudo profissionais integrantes da equipe multiprofissional do CAPS II e do CAPS AD III (Álcool e Drogas) do município de Palmas/Tocantins. O CAPS II, localizado na região sul, é destinado ao tratamento de pessoas com sofrimento psicológico e transtornos mentais graves e persistentes. Já o CAPS AD, localizado na região norte, é especializado em transtornos pelo uso de álcool e outras drogas e atende à população que sofre com transtornos decorrentes do uso de substâncias psicoativas. Ambos funcionam o dia inteiro, sendo serviços de porta aberta, sem encaminhamento para o atendimento. Ambos possuem equipe multiprofissional e apresentam, em sua maior demanda de atendimento, pessoas com sintomas de depressão e ansiedade, que vivem rompimento de laços sociais e familiares e vulnerabilidade social.

A quantidade de entrevistados foi definida pela saturação dos dados, isto é, constatação do esgotamento de novas informações obtidas (Glaser \& Strauss, 1967). Assim, a coleta de dados foi interrompida a partir da percepção da integração entre os dados e a literatura, conforme Glaser e Strauss (1967). A pesquisa obteve 09 entrevistados, dentre enfermeiros(as), terapeutas, recepcionistas, educador físico e técnicos de enfermagem (Tabela 1). Além disso, foi efetuada entre novembro de 2019 e janeiro de 2020.

\section{Tabela 1}

Relação de Participantes Entrevistados

\begin{tabular}{|c|l|l|l|l|l|}
\hline Participante & Idade & Sexo & $\begin{array}{l}\text { Formação ou } \\
\text { cargo } \\
\text { ocupado }\end{array}$ & $\begin{array}{l}\text { Tempo de } \\
\text { Atuação } \\
\text { Profissional }\end{array}$ & $\begin{array}{l}\text { CAPS de } \\
\text { atuação }\end{array}$ \\
\hline E1 & 47 & Feminino & Enfermeira & 19 anos & II \\
\hline E2 & 23 & Feminino & Enfermeira & 01 ano & II \\
\hline E3 & 48 & Feminino & $\begin{array}{l}\text { Téc. de } \\
\text { Enfermagem }\end{array}$ & 13 anos & II \\
\hline
\end{tabular}


Silva Filho, J. B. da, Nascimento, A. C. P. do, \& de Castro, G. H. C.

\begin{tabular}{|l|l|l|l|l|l|}
\hline E4 & 52 & Feminino & $\begin{array}{l}\text { Recepcionist } \\
\text { a }\end{array}$ & 10 anos & II \\
\hline E5 & 44 & Feminino & $\begin{array}{l}\text { Assistente } \\
\text { Social }\end{array}$ & 11 meses & II \\
\hline E6 & 38 & Feminino & $\begin{array}{l}\text { Terapeuta } \\
\text { Ocupacional }\end{array}$ & 12 anos & II \\
\hline E7 & 27 & Masculino & Enfermeiro & 04 anos & AD \\
\hline E8 & 36 & Feminino & Enfermeira & 10 anos & AD \\
\hline E9 & 23 & Feminino & $\begin{array}{l}\text { Profissional } \\
\text { de Educação } \\
\text { Física }\end{array}$ & 02 anos & AD \\
\hline
\end{tabular}

Os critérios de inclusão foram: ser participante da equipe multiprofissional do CAPS e CAPS AD III; ser recepcionista, assistentes administrativos e demais profissionais que atendam os usuários; ser residentes multiprofissional ou de medicina atuantes. Foram adotados como critérios de exclusão: profissionais que estivessem de licença ou férias e; profissionais que não aceitassem participar da pesquisa. Deste modo, todos os participantes assinaram o Termo de Consentimento Livre e Esclarecido (TCLE).

As entrevistas seguiram o modelo semiestruturado, em que por meio de perguntas abertas e fechadas, houve a exploração do tema com o pesquisado, seguindo um roteiro de perguntas predefinido, mas de maneira espontânea, conduzindo assim a entrevista como uma conversa informal (Boni \& Quaresma, 2005), versando sobre: trajetória profissional; rotina de trabalho; percepção sobre perfil de usuários; preparo e capacitação para atendimento de travestis e transexuais; percepção acerca de dificuldades/especificidades do atendimento; percepção a respeito da vivência dessas pessoas; e a relação de identidades de gênero com o plano de cuidado e a condição de saúde do paciente. Os participantes, após aceitarem o TCLE, conforme Resolução CONEP n n $^{\circ}$ 466/12 (Brasil, 2012b), foram entrevistados no próprio CAPS em que trabalhavam, em sala reservada que garantisse o sigilo. 
As entrevistas foram gravadas em áudio e, posteriormente, transcritas. Os participantes foram informados de que o conteúdo das entrevistas serviria aos fins de pesquisa científica, assim como o sigilo de suas identidades foi preservado, de modo que, na etapa de apresentação dos resultados, se convencionou identificar os entrevistados pelo uso de códigos aleatórios para cada entrevistado (E1, E2, [...], E9).

As entrevistas foram analisadas empregando-se o Método HermenêuticoDialético, que permitiu interpretar os relatos de forma que as falas dos sujeitos entrevistados fossem consideradas em seu contexto social e histórico e de localização política do grupo estudado (Minayo, 2002). Os dados foram ordenados, classificados e categorizados pelo que surgiu como relevante, sendo, por último, finalmente discutidos. A análise possibilitou tomar os enunciados mais relevantes, constituindo cinco categorias, apresentadas e discutidas a seguir.

\section{Resultados e Discussão}

Discriminação nos espaços sociais e o perfil do paciente trans

Em revisão da literatura sobre acesso de pessoas trans à saúde (Rocon e cols., 2020), a discriminação nos próprios serviços de saúde destinados ao cuidado foi uma das principais categorias proeminentes ao longo de diversas pesquisas. Nessa subseção, aborda-se como a discriminação social contra trans pode reverberar no cotidiano de serviço dos CAPS.

Sehnem e cols. (2017) consideram que a marginalização que as pessoas trans vivenciam as colocam em um complexo quadro de vulnerabilidade no quesito acesso à saúde. Por não corresponderem ao padrão hegemônico de sexo e gênero, pessoas trans fazem parte de um grupo social ao qual não é garantido o exercício da cidadania (Bento, 2008; Muller \& Knauth, 2008). Estima-se, inclusive, que o Brasil seja um dos países com as maiores taxas de homicídio para a população transgênero (Corrêa e cols., 2020). Além disso, um estudo que avaliou a prevalência do pensamento suicida entre pacientes trans identificou que "questões sociodemográficas [...] compõem esses fatores, demonstrando possíveis relações com a ideação suicida" (Corrêa e cols., 2020, p. 13).

Esses indivíduos sofrem com preconceito, discriminação, sentimento de invisibilidade e violação de todas as naturezas promovidos pela sociedade no 
mundo atual. Tais condições dificultam ainda mais o acesso dos transexuais aos serviços públicos, entre eles educação, saúde, meios sociais e segurança pública. Eles apresentam ainda como agravantes de sua saúde riscos à integridade psíquica, física e moral, causando redução da qualidade de vida e promovendo danos à saúde mental e física principalmente, sendo os processos de sofrimento e sensação de inferioridade os principais exemplos (Corrêa e cols., 2020, p. 14).

Nesse sentido, o acesso de pessoas trans aos CAPS tem aumentado, conforme sugerido pelos entrevistados, o que sugere a necessidade de maior preparo destes profissionais para lidar com as demandas trans e traz implicações para a assistência, o atendimento e o cuidado da população transexual. [F1] considera necessário considerar a questão do preconceito.

[F1]: É um perfil que está aumentando cada vez mais. Você tem muita gente vindo. Eu já fiz vários atendimentos e a gente vê que é uma população que está aumentando por algumas razões, especialmente por causa da sociedade, que eles acabam deprimindo, eles acabam entrando em sofrimento. $\mathrm{O}$ impacto emocional maior, principalmente o preconceito, eles acabam entrando em sofrimento e procurando um CAPS [E1]. Rev. Polis e Psique, 2021; 11(3): 56 - 80
O conteúdo de [F1] coaduna com estudo sobre representações sociais elaboradas por profissionais de saúde acerca da transexualidade, em que Santos, Shimizu e Merchan-Hamann (2014), identificaram, no núcleo das associações realizadas pelos profissionais, a forte carga de preconceito a que pessoas trans são socialmente submetidas. Nesse sentido, enunciados [F2-F4] confirmam como as diversas violências contra pessoas trans nos múltiplos espaços sociais, fundamentadas no preconceito, podem realmente contribuir para um risco maior de adoecimento mental (Corrêa e cols., 2020).

[F2]: $\mathrm{O}$ adoecimento vem muito mais por essa questão do preconceito, de não ser aceito ou então de não encarar. E a maioria que chega à tentativa de suicídio não se sente de jeito nenhum pertencente a esse mundo, a essa sociedade. O tempo todo querendo fugir disso, se negar, não é? O quê que é? A sua essência [E6].

[F3]: É um perfil de paciente que tem um tipo de sofrimento desde praticamente a sua infância. [...] Então como eles vêm e têm um impacto emocional de rejeição, de preconceito, de isolamento familiar, essa população tem que provar todos os dias que é capaz, que é normal, que é merecedora de conquista, 
que não é diferente de qualquer um outro. Elas acabam adquirindo esse sofrimento. [...] Então vai chegando um ponto que é igual um copo, se botar água, ele enche, ele vai transbordar. Então essas pessoas elas vêm sofrendo, sofrendo, sofrendo e elas acabam extravasando [E1].

[F4]: De tanto a família discriminar, a sociedade discriminar e a pessoa querer se transformar em uma coisa que ele não consegue, ele acaba adoecendo. 'Por que como que eu vou querer ser uma coisa que eu não consigo?' 'Eu tento, tento, tento'. 'Minha mãe não está feliz, minha irmã não está feliz, a sociedade não está feliz’ [E3].

Essas vivências e violências podem levar a ideias suicidas (Corrêa e cols., 2020), tal como dispõe [F2]. Já [F3] descreve impactos emocionais que pessoas trans vivenciam ao passar por diversas esferas sociais e sobre como isso pode refletir em termos de saúde mental, dado que isso os acompanha desde a infância, compreendendo a relação familiar. Assim, compreende-se, à luz de Soich (2019), que a família seria um dos (senão o principal) ator(es) no processo de exclusão infligido à pessoa trans. [F4], por sua vez, considera que o preconceito perpetrado pela família e pela sociedade, somados ao conflito interno em torno da identidade de gênero, podem contribuir para o adoecimento, resultando em um sistemático sofrimento psíquico (Corrêa e cols., 2020). A principal marca desses enunciados é a de que pessoas trans buscariam reconhecimento e aceitação, mas, com o enfraquecimento dos vínculos, o adoecimento mental poderia ocorrer.

Nesse aspecto, a não-aceitação (transfobia internalizada) emergiu nos fragmentos [F6] e [F7]. Todavia, chama a atenção o fato da noção de transexualidade, por parte dos profissionais, seguir ótica similar à identificada por Santos, Shimizu e Merchan-Hamann (2014), em que "o fato de transexualidade ser confundida como sinônimo de homossexualidade, por exemplo, evidencia o distanciamento dos profissionais de saúde em relação ao tema" (Santos, Shimizu \& Merchan-Hamann, 2014, p. 4552).

[F6]: Elas, com certeza, a identidade de gênero delas influenciou, tanto para a prostituição, talvez para ir para a droga. O que a gente percebia muito lá no CAPS eram pessoas que usavam droga para reprimir a homossexualidade, acontece muito. Acontece aqui também. Pessoas que chegam no acolhimento, tem ansiedade, tem depressão por causa da repressão da homossexualidade. Ou porque 
não se aceitam ou porque a família não aceita [E3].

[F7]: As pessoas falam que não têm preconceito, mas isso é uma hipocrisia. Todo mundo tem preconceito. Eu acredito que todo mundo tem preconceito, sim. E até mesmo aquelas pessoas que não falam: 'ah, eu não tenho preconceito, eu aceito'. Não sei, mas lá no fundinho a gente sempre tem um preconceito sim [...] [E5].

Com base em [F6] e [F7], depreende-se que a inserção no contexto social, por si só, se perfaz como fator preponderante do adoecimento para pessoas trans, tendo em vista que instituições basilares da convivência rejeitam essas expressões de gênero. Todavia, no primeiro fragmento é recobrado o estigma da prostituição com relação a pessoas trans, uma vez que a população travesti é frequentemente associada a essa atividade. Ainda, é permanente a discriminação silenciosa na conduta de profissionais de saúde, tendo em vista que o estigma imputado às pessoas trans é o da prostituição e de relação com o HIV, que as enquadra como grupos de risco, quando, em realidade, os comportamentos é que seriam de risco, e não os grupos já marginalizados (Muller \&Knauth, 2008; Sehnem e cols., 2017).
Abordagem da equidade para pacientes trans

Outro grupo de enunciados é o de que a equidade no atendimento para o caso transexual, poderia acarretar privilégio ou tratamento diferenciado de modo a favorecer tal público, o que é sugerido nos fragmentos [F8-F10].

[F8]: Você não pode traçar um plano de cuidado por a pessoa ser transexual. Você tem que ter o plano de cuidado somente de acordo com a necessidade da pessoa, independente do que ela é. [...] Ela é importante porque é importante para a pessoa, mas ela não pode ser considerada.... mudar um plano de atendimento em função da opção da pessoa. Ela tem que ser tratada como uma pessoa... [...] Tem que ser direcionado para o ser humano, o cuidado. Não pela opção dela. Deve ser respeitada e tratada de acordo como qualquer um outro [...] Não tem critério nem diferenciação no atendimento. Nós queremos tratar o ser humano como ser humano, independente de raça, de cor, de religião, de qualquer outra coisa [E1].

[F9]: [...] claro que a gente tem que olhar para as particularidades da pessoa, mas acredito que a gente não pode tirar ela, isolar ela do grupo, tipo: 'ah, você é trans, 
fique aqui, vou te cuidar diferente dos outros'. [...] Cada paciente, mesmo que tenha um transtorno parecido, por exemplo, duas pessoas com esquizofrenia, a gente tem que tratar diferente [E2].

[F10]: [...] Tem que ser tratado como qualquer outra pessoa, porque não é por conta da escolha dele que ele tem que ser diferente. Eu penso assim. Então assim, eu acredito que a gente tem que ter aquela questão da equidade, não é? [...] O que eles falam...tratar os iguais diferentes? Os diferentes iguais? Assim. Mas eu acho que ele tem que ser tratado como todos os outros. Não vejo que tem que ser especial porque é um ser humano como todos, todos os outros. Não tem que ser diferente [E5].

[F8-F10] compreendem de modo equivocado a equidade, uma vez que entendem que não se deve dispensar um tratamento diferenciado para transexuais e travestis nos CAPS. Salienta-se que tal equívoco é demonstrado na ideia de o cuidado trans ser como o de qualquer outra pessoa, desconsiderando elementos, que tangenciam à identidade de gênero desconforme ao padrão binário de gênero e que resultam em violências (Bento, 2008).

Outro equívoco, presente nos excertos [F8] e [F10], é o de que a transexualidade e a travestilidade seriam fruto de uma "opção" ou uma "escolha", quando o debate vai além de uma escolha deliberada. Como colocado por Santos, Shimizu e Merchan-Hamann (2014, p. 4552), termos como escolha ou opção “atribuem à questão caráter demasiadamente individual e subjetivo. É como se cada indivíduo sozinho fosse responsável por suas próprias escolhas, e pelas consequências advindas delas, sem considerar questões mais amplas de sociedade e cultura". Logo, a falta de diferenciação no atendimento seria o que, justamente, resultaria em violação da equidade, tendo em vista que se, por um lado, este preconiza o atendimento igual a todos, é porque também incentiva um tratamento desigual a outros grupos, na medida de suas desigualdades (Brasil, 1988; 1990; 2013).

Nesse mesmo sentido, de desconsiderar especificidades da população trans, há em [F9], por exemplo, certa confusão ao comparar a questão de gênero e os preconceitos dela advindos como análogo a outras patologias, a exemplo da esquizofrenia, sugerindo que à medida em que são consideradas particularidades, também se deve ter cautela na diferenciação das pessoas trans em relação às demais frequentadoras do CAPS. Essa confusão foi perceptível 
também nas entrevistas dos outros participantes, principalmente a respeito dos conceitos de identidade de gênero. Os entrevistados mostraram pouco entendimento a respeito da vivência trans, por vezes confundindo identidade de gênero com orientação sexual. No entanto, a própria entrevistada se contradiz ao afirmar que transtornos parecidos requerem assistências diferentes, mediante as peculiaridades. [F10], por sua vez, demonstra resistência em dispensar um tratamento diferente, o que fica patente na hesitação em rememorar o princípio constitucional da equidade, seguida da dupla afirmação sobre não tratar diferente e tratar de maneira comum aos demais.

Depreende-se desse grupo de fragmentos que há a noção de que equidade no atendimento para transexuais e travestis pode presumir um suposto privilégio a esta população. Logo, o traço principal destas concepções é a ambiguidade, pois na medida em que se advoga por um não tratamento diferenciado, ele é compreendido como um privilégio. Isso promoveria dificuldades no próprio plano terapêutico utilizado, como salientado a seguir.

[F11]: [...] a gente também não tem que 'ah, porque a pessoa ela é gay ou ela é assim, vamos tratar ela diferente'. Não. A Rev. Polis e Psique, 2021; 11(3): 56 - 80 gente tem que tratar todos iguais. Mas a gente também procura fazer esse acompanhamento de fora, vamos dizer assim, mais especial, não é? Porque a gente sabe que ela é uma pessoa que ela já traz toda uma carga de fora e aí a gente procura no serviço diminuir essa carga [E5].

[F12]: Assim, independente de ser homossexual ou não, travesti ou não, eles são iguais. Eles vêm, passam um tempo, depois vão embora, passa um tempo sumido, eles fazem aquele...monta um grupo, um PTS, que é um plano terapêutico para eles. Eles não cumprem. As vezes ficam um tempo até se desintoxicarem, se organizar um pouquinho. Aí eles vão de novo. E assim é normal. Assim, não tem diferença porque eles se comportam igual um hétero, entendeu? Ele é usuário. Não tem diferença [E8].

No primeiro fragmento, "fazer esse acompanhamento por fora" é sugestivo de como outras táticas podem ser utilizadas pelos profissionais de modo a proporcionar o acolhimento, para além do que preconiza a Carta do Usuário do SUS (Brasil, 2012a), no qual busca-se um acompanhamento mais especial, por conta do preconceito, referido nas expressões "carga de fora". Todavia, esta afirmação também é 
elaborada por uma ambiguidade. No último fragmento, sugere-se que essa igualdade, levada ao plano terapêutico, experimentaria certa resistência por parte das travestis e transexuais que acessam, em especial, o CAPS AD III.

No limite, os excertos anteriores desta seção sugerem que falhas no acolhimento podem, direta ou indiretamente, acarretar abandono do processo terapêutico, pois, como dito por Sehnem e cols. (2017), a questão abordada vai muito além da dificuldade de inserção, envolvendo a permanência em locais que muitas vezes não se apresentam acolhedores.

\section{Nome social como porta de entrada}

$\mathrm{O}$ respeito à identidade ou expressão de gênero, dada, principalmente, a partir do reconhecimento do nome social de pessoas trans é uma das categorias de análise mais representativas na literatura que discorre sobre o acesso, em geral, de tais indivíduos a serviços de saúde, especialmente públicos (Arán, Murta, \&Lionço, 2008; Muller \&Knauth, 2008; Rocon e cols., 2016; Rocon e cols., 2018; Rocon e cols., 2020; Sehnem e cols., 2017).
O Ministério de Saúde, por meio da Portaria $n^{\circ} 1.280 / 2009$, lançou a Carta dos Direitos dos Usuários do SUS (Brasil, 2012a). Essa carta permite que, em formulários de identificação, o usuário preencha com o nome que deseja ser chamado, como forma de conceder $\mathrm{o}$ direito "ao atendimento humanizado, acolhedor e livre de discriminação" (Rocon e cols., 2016). Porém, em 2011, com a "Política Nacional de Saúde Integral de Lésbicas, Gays, Bissexuais, Travestis e Transexuais" e por intermédio da Portaria $n^{\circ} 2.836$ é que se normatizou o "uso do nome social de travestis e transexuais, de acordo com a Carta dos Direitos dos Usuários dos SUS” (Rocon e cols., 2016, p. 2519). A seguir, relata-se a compreensão acerca do nome social e situações específicas enfrentadas nos CAPS.

[F13]: Tipo, a [nome de pessoa trans], o nome dela de verdade, de batismo, é [nome biológico da pessoa trans], só que ela não gosta que chame ela por esse nome. [...] Então, assim, no prontuário eletrônico, no PTS que as meninas montam, em exames laboratoriais, tudo que vai fazer com relação à [nome da pessoa trans], a gente pronuncia o nome dela, que ela gosta de ser chamada, o nome social. Não chamamos pelo nome biológico [E8]. 
[F14]: Existe o cuidado. É anotado no prontuário o nome social [E1].

[F15]: Às vezes, é meio complicado assim, porque de repente vem uma pessoa que o nome no documento é o nome que a mãe colocou, que registrou, mas a pessoa, às vezes, usa um outro nome, não é? Porque é trans ou não quer assumir a identidade a qual nasceu então, às vezes, a gente fica...bom, eu, às vezes, fico meio em dúvida quando a pessoa está só com a identidade [...] Será que a pessoa não vai ficar constrangida? Porque aí depois quando ele passa pelo corredor, que escuta toda a história, quando faz um documento...aí tem lá, tem o nome da identidade, aí vem outro nome, que é o qual a pessoa está usando [E3].

[F16]: [...] Às vezes vem com um nome na ficha quando eu pego lá no acolhimento, está escrito um nome, e aí quando eu vou olhar no e SUS tem outro nome. [...] Eu quero até conversar e saber o que aconteceu, porque isso aconteceu comigo inclusive sexta-feira passada. Porque colocaram um nome feminino mas a pessoa tinha um nome masculino. E aí na hora que eu fui chamar eu chamei por um nome. E, enfim, gerou um certo constrangimento, eu acho, assim, para o usuário e para mim. Eu acho assim, sabe, uma falta de comunicação, assim, na ficha, mesmo que não precisava. Porque podia ter colocado só o nome que ela se identificou [E6].

Apesar de [F13] e [F14] indicarem que há o cuidado com o nome social, em nível de equipe, a tratativa é permeada pela incerteza. Como discorrem [F15] e [F16], que sugerem insegurança da equipe sobre como lidar com a questão, evidenciando que não há coesão na compreensão do nome social.

A questão do nome social possui relevância no acesso de pacientes transexuais aos estabelecimentos de saúde, sobretudo do SUS, pois, "quando solicitam para o profissional utilizar o nome social e não o civil, e o mesmo não é atendido, gera-se uma situação humilhante, sendo este o primeiro impedimento das travestis em ter o acesso a um dos seus direitos como cidadã, a saúde" (Sehnem e cols., 2017, p. 1680).

Segundo Muller e Knauth (2008), o desrespeito ao nome social, constitui-se numa forma de discriminação, mas, para além disso, é algo que é inerente à falta de qualificação dos profissionais perante a questão, não sendo uma justificativa para tal atitude (Muller \& Knauth, 2008). Consequentemente, dado o desrespeito à identidade de gênero, refletida no nome, pessoas trans "dificilmente se dirigem às 
instituições de saúde, mesmo em casos graves" (Rocon e cols., 2020, p. 6).

Estratégias de acolhimento, cuidado e assistência dispensados

Segundo Sehnem e cols. (2017, p. 1681), "o acolhimento configura-se como importante instrumento [...], visando à melhoria da qualidade da assistência à saúde voltada para as necessidades da população [...], a partir da construção de um diálogo entre o serviço, os profissionais de saúde e a comunidade". Os enunciados que seguem retratam como vem ocorrendo o acolhimento, o cuidado e assistência em âmbito dos CAPS pesquisados.

[F17]: [Sobre o cuidado] Normal igual aos outros. As mesmas perguntas, o jeito de tratar é o mesmo. Se tiver que acolher vai ser igual para todos. Aí eles ficam, por exemplo, um travesti que entra ele fica junto com as mulheres, ele não coloca junto com os homens [E8].

[F18]: A travesti, na maioria das vezes que ela fica no acolhimento noturno, ela fica na suíte feminina junto com outras mulheres. Em um certo dia, houve uma tensão de que uma usuária que também estava poderia não aceitar ficar no mesmo quarto que ela. [...] Eu lembro de um enfermeiro falar sobre isso: "será que a usuária vai aceitar ficar no mesmo quarto que ela?". Eu lembro dessa questão. [...] Mas, assim, a não ser que ela não esteja no acolhimento noturno, ela sempre fica no quarto feminino [E7].

Em [F17], a ideia de equidade, ainda que reforçada pela afirmação de um tratamento normal, igual a qualquer paciente, é transposta para a prática em ações como a de não deixar mulheres transexuais na mesma ala masculina. No entanto, [F18] indica que, por vezes, há tensão em relação à presença de pacientes travestis em ambientes destinados a mulheres cisgêneras. Há o receio por parte da equipe em dispensar um tratamento equitativo, sob temor de represálias de outras pacientes. Esse achado desvela uma tensão no acolhimento, como abordaram Oliveira e Romanini (2020, p. 6), na qual “a vinculação estabelecida entre profissionais e usuárias se constrói de forma muito frágil, visto que elas se sentem constantemente avaliadas, ao invés de acolhidas". De outra parte, o acolhimento pode valer-se de estratégias de cuidado balizadas pela dimensão da confiança, como sugerem [F19] e [F20].

[F19]: Lá no AD, os travestis que eu já atendi, eles se prostituíam. Então, eu tentava em todo contato que eu tinha, fazer 
essa orientação, de usar a camisinha, de tomar cuidado com a saúde, de realmente perceber o seu corpo, olhar, qualquer coisa que aparecer, que você ver que não estava lá, a quanto tempo...procurar uma unidade de saúde. Era essa a educação em saúde, vamos dizer assim, que eu fazia, as orientações [E2].

[F20]: Eu já ouvi falar, já ouvi eles falando várias vezes. Até sobre problemas mais graves de saúde. Ele já chegou para mim e já falou: “olha, eu tenho isso"..."eu estou arrasado". E aí a gente fica...imagina a pessoa chegar e falar assim para a gente assim. A gente sente aquele choque, não é? Mas a gente não pode deixar transparecer, não é? Ao mesmo tempo é gratificante pela forma dele confiar. Confiar na gente para falar [E4].

[F19] indica um tratamento que busca acolhimento a partir da orientação e instrução destinado à população travesti e transexual que trabalhava com prostituição. [F20] indica como é a dimensão do acolhimento na prática, sugerindo a empatia desde o primeiro contato consolidado entre profissional e paciente travesti e transexual. Destaca-se que é patente nos fragmentos a reiterada utilização do pronome de gênero masculino por parte de profissionais de saúde (ainda que não intencional), o que Rev. Polis e Psique, 2021; 11(3): 56 - 80 confirma um agudo desconhecimento das especificidades de pessoas trans, como é o caso da travesti, identidade que só se contempla com pronome feminino (Bento, 2008; Santos, Shimizu, \& MerchanHamann, 2014). Assim, é no campo da linguagem que se produzem outras discriminações indiretas, como traz [F21].

[F21]: Não é porque eu tenho a minha cultura que eu não vou adentrar a cultura do outro para conversar sobre determinados assuntos. Por exemplo, teve uma vez que - eu participo de um grupo que coordeno, um grupo de leitura aqui na leitura, estava falando sobre travestis e ela estava presente. E aí alguns usuários começaram a fazer piadinha e aí teve um momento que ela tomou a palavra e falou a opinião dela sobre isso. E eu falei que nós tínhamos que respeitar porque é a opinião dela. Cada um tem a sua e a dela tem de ser respeitada também. Não é porque eu discordo que eu não vou dar o espaço para ela [E7].

[F21] relata que episódios de discriminação indireta, ocasionadas em piadas que geram constrangimento, ocorrem em sessões realizadas no CAPS, mas que a partir da postura reativa de uma paciente trans, ela afirma ter conseguido, de certa maneira, contornar a situação. Além disso, o emprego do humor a serviço 
da retroalimentação de estigmas são formas deliberadas de se ferir o que preconiza a Portaria 2.803/2013, artigo $2^{\circ}$, item 3, cuja diretriz é a de que o acolhimento à pessoa trans seja "livre de discriminação, por meio da sensibilização dos trabalhadores e demais usuários e usuárias da unidade de saúde para o respeito às diferenças e à dignidade humana, em todos os níveis de atenção" (Brasil, 2013).

[F22]: [...] Não que a gente queira impor para a pessoa que ela mude de atitude frente a isso [prostituição]. Não é nenhum problema e nem impede de ela fazer o tratamento aqui. Mas o ciclo é o mesmo, sabe? O ciclo vinha sendo o mesmo, assim de recaída-acolhimento, recaída-acolhimento. E relacionado à questão de prostituição e drogas [E7].

[F23]: Alguns têm essa dificuldade. [...] Quer ajuda mas às vezes fica constrangido porque você sabe que há ainda uma discriminação muito grande. Embora a informação está aí [sic], mas eles ainda temem como que ainda vai ser recebido, como que vai ser o atendimento e alguns eu percebo que têm uma certa dificuldade, às vezes, de se expressar, de procurar ajuda. Eu acho que existe essa dificuldade da parte de alguns [E3].
[F24]: Eu conversava com ela assim, via ela sentada e tudo aí conversava, ela participava dos meus grupos, eu observava, aí se eu notava alguma coisa, 'ah, fulano de tal é um pouco depressivo, está um pouco assim', aí eu comunicava com o técnico dela: 'olha, fulano de tal está desse jeito, eu acho que a gente...será que ela não adere à psicoterapia?' [E2].

[F22-F24] abordam os principais complicadores que podem sugerir a descontinuidade ou até mesmo o não acesso por parte de indivíduos trans nos CAPS, pois, assim como inúmeros estabelecimentos, podem ser lugares em que possivelmente serão alvos de má acolhida e discriminação (Muller \& Knauth, 2008). Isso desvela a tarefa de transpor o desafio que é inserir esta população no âmbito dos serviços de saúde (Sehnem e cols., 2017). De acordo com Rocon e cols. (2018), a discriminação nesses estabelecimentos pode impactar no cuidado, ocasionando "absenteísmo; abandono de tratamentos em andamento e de consultas agendadas; e resistência na busca por serviços de saúde" (Rocon e cols., 2018, p. 50).

Assim, os relatos indicam que o cuidado à saúde mental da população trans ainda é contingente, o que indica respostas pouco estruturadas a necessidades, à 
medida em que elas vão surgindo. $\mathrm{O}$ acolhimento inadequado é uma das principais categorias de análise, que têm sido contempladas e discutidas em diversas pesquisas sobre pessoas trans e acesso à saúde (Muller \&Knauth, 2008; Rocon e cols., 2020; Sehnem e cols., 2017). Esse acolhimento é entendido como inadequado, pois "impede a inclusão e a escuta qualificada das demandas em saúde da população trans usuária dos serviços de saúde" (Rocon e cols., 2020, p. 11).

Segundo Rocon e cols. (2020), a Carta de Direitos dos Usuários do SUS é insuficiente para fazer face a um "atendimento humanizado, acolhedor e livre de qualquer discriminação" (Rocon e cols., 2020, p. 5), mesmo porque situações de humilhação, discriminação e chacota, dentre outras, podem levar “a população trans a evitar adentrar os equipamentos e serviços de saúde, o que reflete na piora de suas condições de saúde" (Rocon e cols., 2020, p. 6).

Perspectivas acerca do preparo ante à questão

Emergiu no decurso da conversação uma quinta categoria, que compreende enunciados acerca de pontos a serem observados para que haja melhoria no Rev. Polis e Psique, 2021; 11(3): 56 - 80 tratamento para transexuais e travestis, isto é, entende-se que o tratamento para transexuais ainda se encontra numa zona do que é idealizado, e não o real. Todavia, Rocon e cols. (2018, p. 50), observam como indispensável a equipe estar integrada "no processo de acolhimento e cuidado por meio da gestão coletiva dos processos de trabalho".

[F25]: $\mathrm{Eu}$ acho que falta muito preparo mesmo assim e, principalmente, para se construir PTS. Não só esse grupo mas outros segmentos também assim vulneráveis. Não só de travestis e transexuais.[...]. Triste dizer mas que deveria ter um PTS porque a pessoa tem que ser conduzida para grupo terapêutico e a gente está em um momento que não estamos tendo o que ofertar de projeto terapêutico. E aí o que eu fiz foi, na verdade, falar do ambulatório trans, não é? Saber se a pessoa conhecia, se tinha interesse, fazia parte do projeto dela e foi a única coisa que eu fiz. Mas aqui de dentro do CAPS mesmo eu não tive o que ofertar, dentro dessa discussão, dentro dessa temática de gênero e sexualidade [E6].

[F26]: Pois é, já teve alguns treinamentos. [...] Ia para o Rio de Janeiro. Ia ter um treinamento lá e tal. Eles disseram que iam passar para a equipe, mas nunca passou. Assim, às vezes, tem as 
reuniões técnicas, não é? A gente não tem tempo nem de participar dessa reunião técnica porque não pode sair da recepção. A gente fica sozinho. E aí toda hora chega gente. E aí às vezes são decididas coisas na reunião. Também são passadas informações e a gente que fica lá, a gente fica sem saber direito, não é? [E4].

[F27]: Eu confesso que eu tenho dificuldade em lidar com o assunto justamente por não ter apropriação sobre isso. Mas, no acolhimento, quando você percebe que isso está atrelado ao sofrimento atual dela, isso faz toda diferença, você reconhecer essa questão [E9].

A falta de qualificação é identificada nos enunciados acima, sendo uma categoria recorrente ao longo de várias pesquisas, conforme identificou-se na de revisão de literatura de Rocon e cols. (2020), que assim entenderam a questão trans e o acesso à saúde no cenário brasileiro:

[...] os estudos evidenciam um 'efeito cascata' na produção de sofrimento e adoecimento na população trans. Os mesmos estudos que afirmam o desrespeito ao nome social e outras expressões da trans-travestifobia institucional dos serviços de saúde, como principal barreira de acesso, também apontam o abandono de importantes tratamentos em andamento [...] (Rocon e cols., 2020, p. 14).

Conforme Sehnem e cols. (2017), o despreparo é corriqueiro no atendimento à população trans no âmbito dos estabelecimentos de saúde, que atravanca um acolhimento eficiente. Compreende-se que a "educação permanente pode ser o caminho para esse processo junto aos profissionais de saúde, além de que a participação popular da comunidade LGBT se faz necessária" (Sehnem e cols., 2017, p. 1682). Segundo Rocon e cols., é preciso “elaborar programas de educação e campanhas permanentes sobre o direito de acesso ao sistema de saúde livre de discriminação e com uso do nome social" (Rocon e cols., 2016, p. 2517).

Assim, um acolhimento e atendimento adequado perpassa pela maior qualificação dos profissionais de saúde, de modo a mitigar consequências para a saúde mental de pessoas trans, e, com isso, prejuízos para a saúde pública (Muller $\&$ Knauth, 2008). Torna-se significativa "a formação continuada para trabalhadores da saúde, com o objetivo de reverter a realidade da discriminação, desrespeito ao nome social e dificuldade de diálogo entre profissionais e usuários trans, condições que limitam o acesso à saúde" (Rocon e cols., 2018, p. 43). 
Rocon e cols. (2018) defendem ainda a realização de ações de "educação permanente para os trabalhadores em saúde". Propõem que "a realização de palestras e seminários sobre diversidade sexual para profissionais de saúde com orientações sobre respeito às identidades de gênero trans e ao nome social" (Rocon e cols., 2018, p. 50).

Desta forma, pode-se dizer, a partir dos achados, que a efetividade do cuidado trilha pela garantia do processo terapêutico humanizado, considerando iniquidades sociais enfrentadas (como preconiza o Sistema Único de Saúde) por pacientes trans.

\section{Considerações Finais}

O objetivo deste estudo foi analisar a assistência à saúde mental da população trans em dois centros de Atenção Psicossociais (CAPS) de uma capital brasileira. A pesquisa indicou enunciados afirmando que o acesso do público trans aos CAPS tem aumentado, o que sugere a necessidade de maior preparo da equipe multiprofissional para lidar com as demandas trans, trazendo implicações para processos de assistência, atendimento e cuidado.
Os entrevistados afirmaram reconhecer que a população trans possui uma demanda de saúde mental atrelada às questões da violência e preconceito sociais. No entanto, a compreensão acerca da questão ainda esbarra em estereótipos e preconceitos arraigados na ideia de que ser transexual, por exemplo, seria uma escolha deliberada, ou seja, reforçando que consequências para saúde mental são decorrentes de "opção" por ser transexual, ou até confundindo transexualidade com homossexualidade.

Além disso, por vezes, os profissionais demonstraram desconhecimento em relação às demandas específicas. Isso se evidenciou quando as equipes sustentaram, quase uniformemente, a noção de que equidade seria atendimento igual a todos, desconsiderando as demandas específicas da população trans, que são amparadas, inclusive, em portarias, decretos e cartilhas do próprio SUS. Há insegurança por alguns profissionais em atuar principalmente contra o preconceito, fortemente arraigado em contatos com outros pacientes. Outras vezes, há dificuldades em se estabelecer um tratamento unificado, como no caso do nome social, em que alguns entrevistados 
demonstraram incerteza em relação a este aspecto.

Algumas boas práticas, ainda que pontuais, são exemplificadas como atitudes despendidas para proporcionar o acolhimento de tal população, mesmo que, novamente, não uniforme entre os entrevistados. Destarte, muitos consideraram como relevante que houvesse maior capacitação concernente à temática. Apesar dos complicadores relatados no acesso, no acolhimento e no atendimento, emergiram propostas para assegurar um processo terapêutico mais humanizado e que considere as iniquidades sociais vivenciadas por transexuais.

Considera-se que essa pesquisa contribui em sentido científico e para a práxis multiprofissional em saúde mental. Com isso, espera-se que equipes multiprofissionais tenham, como benefício indireto, futuras capacitações e formações para o atendimento e cuidado da população trans. Pretende-se, ainda, que os resultados possam contribuir para políticas públicas específicas para tal população e educação permanente dos profissionais, sendo referência para futuros ambulatórios integrais de atenção à saúde de pessoas trans.

\section{Referências}

Arán, M., Murta, D., \&Lionço, T. (2009). Transexualidade e saúde pública no Brasil. Ciência \& Saúde Coletiva, 14(4), 1141-1149. doi:10.1590/S141381232009000400020

Bento, B. (2008). O que é transexualidade. São Paulo: Brasiliense.

Bento, B. (2017). A reinvenção do corpo: sexualidade e gênero na experiência sexual. (3a. ed.). Rio de Janeiro: Garamond.

Boni, V., \& Quaresma, S. J. (2005). Aprendendo a entrevistar: como fazer entrevistas em Ciências Sociais. Em Tese, 2(1), 68-80. doi: $10.5007 / \% 25 \mathrm{x}$

Brasil, Senado Federal (1988). Constituição da República Federativa do Brasil. Brasília.

Brasil, Ministério da Saúde.(1990). Lei Federal $n^{\circ} 8.080$, de 19 de setembro de 1990. Brasília.

Brasil, Ministério da Saúde. (2008). Portaria ${ }^{\circ} 457$, de 19 de agosto de 2008. Brasília. Recuperado de http://bvsms.saude.gov.br/bvs/saud elegis/sas/2008/prt0457_19_08_20 $\underline{08 . h t m l}$

Brasil, Ministério da Saúde. (2012a). Carta dos direitos dos usuários de saúde. Brasília. Recuperado de http://conselho.saude.gov.br/bibliot eca/livros/Carta5.pdf

Brasil, Ministério da Saúde. (2012b). Resolução CNS no 466, de 12 de dezembro de 2012. Brasília. Recuperado de https://bvsms.saude.gov.br/bvs/sau 
delegis/cns/2013/res0466_12_12_2 012.html

Brasil, Ministério da Saúde. (2013). Política Nacional de Saúde Integral de Lésbicas, Gays, Bissexuais, Travestis e Transexuais. Brasília. Recuperado de http://bvsms.saude.gov.br/bvs/publi cacoes/politica_nacional_saude_les bicas_gays.pdf

Brasil, Ministério da Saúde. (2013). Portaria $\mathrm{n}^{\mathrm{o}}$ 2.803, de 19 de novembro de 2013. Brasília. Recuperado de http://bvsms.saude.gov.br/bvs/saud elegis/gm/2013/prt2803_19_11_20 13.html

Corrêa, F. H. M., Rodrigues, B. B., Mendonça, J. C., \& Cruz, L. R. D. (2020). Pensamento suicida entre a população transgênero: um estudo epidemiológico. Jornal Brasileiro de Psiquiatria, 69(1), 13-22. doi:10.1590/0047-2085000000256

Davis, D. (2009). Transgender issues in the workplace: HRD's newest challenge/opportunity. Advances in Developing Human Resources, 11(1), 109-120. doi:10.1177/1523422308329189

Glaser B. G., \& Strauss A. L. (1967). The discovery of grounded theory: strategies for qualitative research. New York: Aldine de Gruyter.

Lionço, T. (2008). Que direito à saúde para a população GLBT? Considerando direitos humanos, sexuais e reprodutivos em busca da integralidade e da eqüidade. Saúde e sociedade, 17(2), 11-21. doi:10.1590/S010412902008000200003
Mello, L., Perilo, M., Braz, C. A. D., \& Pedrosa, C. (2011). Políticas de saúde para lésbicas, gays, bissexuais, travestis e transexuais no Brasil: em busca de universalidade, integralidade e equidade. Sexualidad, Salud y Sociedad, (9), 7-28. doi:10.1590/S198464872011000400002

Minayo, M. C. S. (2002). Hermenêutica-dialética como caminho do pensamento social. In: M. C. S. Minayo\& S. F. Deslandes (Orgs.), Caminhos do pensamento: epistemologia e método (pp. 106139). Rio de Janeiro, Brasil: Fiocruz.

Muller, M. I., \&Knauth, D. R. (2008). Desigualdades no SUS: o caso do atendimento às travestis é 'babado'!. Cadernos

Ebape.BR, 6(2), $1-14$. doi:10.1590/S167939512008000200002

Namaste, V. (2006). Transsexual, transgender, and queer: Interview with Viviane Namaste. In Seidman, S., Fischer, N., Meeks, C. (Eds.), Handbook of the new sexuality studies (pp. 193-200). New York, NY: Routledge.

Oliveira, I. D., \& Romanini, M. (2020). (Re)escrevendo roteiros (in)visíveis: a trajetória de mulheres transgênero nas políticas públicas de saúde. Saúde e Sociedade, 29, e170961. doi:10.1590/S010412902020170961

Rocon, P. C., Wandekoken, K. D., Barros, M. E. B. D., Duarte, M. J. O., \& Sodré, F. (2020). Acesso à saúde pela população trans no 
Brasil: nas entrelinhas da revisão integrativa. Trabalho, Educação e Saúde, 18(1), $1-18$. doi:10.1590/1981-7746-sol00234

Rocon, P. C., Rodrigues, A., Zamboni, J., \&Pedrini, M. D. (2016). Dificuldades vividas por pessoas trans no acesso ao Sistema Único de Saúde. Ciência \& Saúde Coletiva, 21, 2517-2526. doi:10.1590/141381232015218.14362015

Rocon, P. C., Sodré, F., Zamboni, J., Rodrigues, A., \& Roseiro, M. C. F. B. (2018). O que esperam pessoas trans do Sistema Único de Saúde?. Interface - Comunicação, Saúde, Educação, 22(64), 43-53. doi:10.1590/1807-57622016.0712

Santos, A. B. D., Shimizu, H. E., \&Merchan-Hamann, E. (2014). Processo de formação das representações sociais sobre transexualidade dos profissionais de saúde: possíveis caminhos para superação do preconceito. Ciência \& Saúde Coletiva, 19, 4545-4554. doi:10.1590/1413812320141911.15702013

Sehnem, G. D., Rodrigues, R. L., Lipinski, J. M., Vasquez, M. E. D., \& Schmidt, A. (2017). Assistência em saúde às travestis na atenção primária: do acesso ao atendimento. Rev. enferm. UFPE online, 11(4), 1676-1684. doi:10.5205/reuol.9763-85423-1SM.1104201716

Soich, M. (2019). A exclusão começa em casa: análise crítica da construção da representação discursiva da identidade de gênero trans em relação à família e a outros atores sociais. Cadernos de Linguagem e Sociedade, 20(1), 173-200.

doi:10.26512/les.v20i1.11184

Tenório, F. (2002). Reforma psiquiátrica brasileira, da década de 1980 aos dias atuais: História e conceitos. História, Ciência, Saúde, 9(1), 25-59. doi:10.1590/S010459702002000100003

Thanem, T., \&Wallenberg, L. (2014). Just doing gender?Transvestism and the power of undergoing gender in everyday life and work. Organization, 23(2), 250-

271.doi:10.1177/135050841454755 9

José Bernardes da Silva Filho é graduado em Psicologia (UFJF) e especialista em Saúde da Família e Comunidade pela Residência Multiprofissional da FESP/CEULP - Ulbra. Possui experiência de trabalho na Atenção Primária em Saúde da Família e em pesquisas sobre gênero, sexualidade, e políticas públicas.

E-mail: bernardesufjf@gmail.com

ORCID: https://orcid.org/0000-0002$\underline{5933-5193}$.

Ana Carolina Peixoto do Nascimento é graduada em Psicologia pelo Centro Universitário Luterano de Palmas CEULP/ULBRA (2016). É também mestre em Ensino em Ciência e Saúde, pela Universidade Federal do Tocantins (UFT). Atua na Psicologia Jurídica (credenciada pelo Tribunal de Justiça do Estado do Tocantins).

E-mail: ana.carol57@hotmail.com. ORCID: https://orcid.org/0000-0002- 
$\underline{2051-7838}$

Gustavo Henrique Carvalho de Castro é graduado em Administração pela Universidade Federal de Viçosa (UFV). É também mestre e doutorando em Administração pelo Programa de PósGraduação em Administração da Universidade de Brasília (PPGA/UnB). Pesquisador do Centro de Cultura e Estudos LGBT no Ambiente de Trabalho e do Núcleo de Diversidade e Crítica Organizacional (NUDICO).

E-mail: gustavo.hc.castro@gmail.com.

ORCID: https://orcid.org/0000-00033920-6404

Submissão: 21/07/2020

$1^{o}$ avaliação: 25/05/2021

Aceite: $30 / 09 / 2021$ 